\title{
Social Isolation and Patient Experience in Older Adults
}

Takuya Aoki, MD, MMA ${ }^{1}$

Yosuke Yamamoto, $M D, P b D^{1}$

Tatsuyoshi Ikenoue, MD, MPH

Yuka Urusbibara-Miyachi, MD, $\mathrm{MHPE}^{2}$

Morito Kise, $M D^{3}$

Yasuki Fujinuma, $M D^{3}$

Sbunichi Fukubara, MD, DMSc, $M A C P^{1,4,5}$

'Department of Healthcare Epidemiology, School of Public Health in the Graduate School of Medicine, Kyoto University, Kyoto, Japan

${ }^{2}$ Medical Education Center, Graduate School of Medicine, Kyoto University, Kyoto, Japan

${ }^{3}$ Centre for Family Medicine Development, Japanese Health and Welfare Co-operative Federation, Tokyo, Japan

${ }^{4}$ Center for Innovative Research for Communities and Clinical Excellence (CIRC2LE), Fukushima Medical University, Fukushima, Japan

${ }^{5}$ Department of General Medicine, Shirakawa Satellite for Teaching And Research (STAR), Fukushima Medical University, Fukushima, Japan

Conflicts of interest: authors report none.

\section{CORRESPONDING AUTHOR}

Shunichi Fukuhara, MD, DMSc, MACP Department of Healthcare Epidemiology, School of Public Health in the Graduate School of Medicine, Kyoto University Yoshida-Konoe-cho, Sakyo-ku, Kyoto 606-8501, Japan

fukuhara.shunichi.6m@kyoto-u.ac.jp

\begin{abstract}
PURPOSE Social isolation has been identified as a major health problem, particularly in the elderly. In the present study, we examine the association between social isolation and patient experience in elderly primary care patients.
\end{abstract}

METHODS This cross-sectional study was conducted in a primary care practicebased research network (28 clinics) in Japan. We assessed social isolation using an abbreviated Lubben Social Network Scale and patient experience of primary care using a Japanese version of the Primary Care Assessment Tool (JPCAT), which comprises 6 domains: first contact, longitudinality, coordination, comprehensiveness (services available), comprehensiveness (services provided), and community orientation. We used a linear mixed effects model to adjust clustering within clinics and individual covariates.

RESULTS Data were analyzed for 465 elderly primary care patients aged $\geq 65$ years. After adjustment for possible confounders and clustering within clinics, social isolation was negatively associated with the JPCAT total score, (mean difference $=-3.67 ; 95 \% \mathrm{Cl},-7.00$ to -0.38$)$. Among the JPCAT domain scores, social isolation was significantly associated with longitudinality, comprehensiveness (service provided), and community orientation scores.

CONCLUSIONS Social isolation was associated with negative patient experience in elderly primary care patients. Raising awareness regarding patient social networks among primary care providers and targeted interventions for socially isolated elderly patients aimed at improving the experience of primary care, especially regarding longitudinality, comprehensiveness, and community orientation, may be warranted.

Ann Fam Med 2018;16:393-398. https://doi.org/10.1370/afm.2257.

\section{INTRODUCTION}

S ocial isolation is defined as a state in which an individual lacks a sense of belonging socially, lacks engagement with others, has a minimal number of social contacts, and displays a deficiency in fulfilling quality relationships. ${ }^{1}$ Social isolation has been identified as a major health problem, particularly in the elderly who lack good social networks that are a key element of social capital. ${ }^{2}$ The negative effects of social isolation on health outcomes are supported by a wealth of evidence. According to previous studies, social isolation is associated with increased risk of all-cause mortality, ${ }_{1}^{3,4}$ mortality from coronary heart disease/stroke, ${ }^{5}$ rehospitalization, ${ }^{6}$ falls, ${ }^{7}$ cognitive decline ${ }^{8}$ and death from suicide. ${ }^{4}$ Moreover, socially isolated older individuals are at risk for negative behaviors, such as heavy drinking ${ }^{9}$ and poor nutritional habits. ${ }^{10}$

Social isolation may influence health outcomes and patient behaviors by having a negative impact on the patient experience. Patient experience is considered the most effective quality measure of patient-centeredness and is defined as providing care that is respectful of and responsive to patient preferences, needs, and values. ${ }^{11}$ Patient experience is known to affect health outcomes through patient behaviors, such as adherence to treatment and health care resource use..$^{12,13}$ Previous studies have reported socioeconomic variation in patient experience, ${ }_{1}^{14,15}$ and a few exploratory quantitative studies have suggested negative associations of social capital 
components with patient experience. ${ }^{16,17}$ Additionally, a previous qualitative study identified social isolation as an unmet need in elderly primary care patients. ${ }^{18}$ Due to a lack of studies, however, an association between social isolation and patient experience of primary care remains unclear. It would be beneficial for primary care providers and policymakers to have a clear understanding of the relationship between social isolation and patient experience.

The aim of this study was to examine the association between social isolation and patient experience in elderly primary care patients.

\section{METHODS}

\section{Design, Setting, and Participants}

The data used for this study were collected from the primary care organizations reciprocal evaluation survey study (PROGRESS) conducted in a primary care practice-based research network ${ }^{19}$ in Japan from October 2015 to February 2016. The PROGRESS was a cross-sectional survey to collect data on patient experience, health-related quality of life, health conditions, health care utilization, clinical process, and sociodemographic characteristics among adult outpatients in primary care. The primary care practice-based research network where this survey was conducted is part of a national network of primary care clinics belonging to the Japanese Health and Welfare Co-operative Federation and the Japan Federation of Democratic Medical Institutions. The 28 participating clinics are distributed in both urban and rural areas (Tohoku, Kanto, Tokai, Kinki, Setouchi, and Sanin) (Supplemental Appendix 1, available at http://www.annfammed.org/ content/16/5/393/suppl/DC1/), with the majority being solo practices. Primary care in these clinics is delivered by family physicians and the majority of patients are aged $\geq 65$ years old. A self-administered questionnaire was distributed to all outpatients aged $\geq 20$ years who visited 1 of the participating clinics within the 3 -day survey period, and the completed surveys were collected via mail.

A total of 644 individuals out of 1,939 adult patients (33.2\%) responded to the PROGRESS. Among them, participants eligible for this study were individuals aged $\geq 65$ years, for whom the clinic serves as their usual source of care. To identify an individual's usual source of care in this study, the 3 questions and the algorithm used in the Japanese version of the Primary Care Assessment Tool (JPCAT) ${ }^{20}$ were the same as those used in the original Primary Care Assessment Tool Adult Expanded Edition ${ }^{21}$ : (1) Is there a doctor that you usually go if you are sick or need advice about your health?; (2) Is there a doctor that knows you best as a person?; and (3) Is there a doctor that is most responsible for your health care?. A patient was considered to have a usual source of care if he or she answered positively to any 1 of the 3 questions.

The ethical committee of the Kyoto University Graduate School of Medicine provided ethical approval for this study (approval number R0184). Written informed consent was obtained from all study participants.

\section{Measures}

\section{Social Isolation}

We used the Japanese version of the abbreviated Lubben Social Network Scale (LSNS-6) ${ }^{22}$ to evaluate the social isolation in elderly individuals (Supplemental Appendix 2, available at http://www.annfammed.org/ content/16/5/393/suppl/DC1/). The LSNS-6, developed by James Lubben, is used for screening and research of social networks in many countries. ${ }^{23}$ The LSNS-6 is a 6-item self-reported scale used to assess social isolation in the adults aged $\geq 65$ years old by measuring perceived social support received from family and friends. This tool assesses the size, closeness, and frequency of contacts in a respondent's social network. The LSNS-6 score is an equally weighted sum of scores on the 6 items. The scores range from 0 to 30 points, with higher scores indicating a better quality of social network. The reliability and validity of the Japanese version of LSNS- 6 have been assessed in a previous study in Japan. ${ }^{22}$ As suggested by Lubben et al, we classified patients with a score of $<12$ points as being socially isolated. ${ }^{23}$

\section{Patient Experience of Primary Care}

We used the JPCAT ${ }^{20}$ as the patient experience measure of primary care (Supplemental Appendix 3, available at http://www.annfammed.org/content/16/5/393/ suppl/DC1/). The JPCAT, based on the Primary Care Assessment Tool Adult Expanded Edition, ${ }^{21}$ was developed with the Delphi method, cognitive testing, and validation study to establish its applicability to the Japanese health care system. This 29-item tool comprises 6 multi-item subscales representing 5 primary care attributes, including first contact, longitudinality, coordination, comprehensiveness, and community orientation (Supplemental Appendix 4, available at http://www.annfammed.org/content/16/5/393/suppl/ DC1/). ${ }^{24}$ The scoring system of JPCAT is structured as follows: each response on a 5 -point Likert scale is converted to an item score from 0 and 4 . The means of item scores in the same domain are multiplied by 25 to yield domain scores ranging from 0 to 100 points, with higher scores indicating better patient experience. The total score is the mean of the 6 domain scores and reflects an overall measure of the quality of 
core primary care attributes. Previous work has shown that the JPCAT has good reliability and validity. ${ }^{20}$ The primary outcome measure in this study is the JPCAT total score, and secondary outcome measures are the domain scores.

\section{Covariates}

Covariates were selected for their known associations with social isolation and patient experience. We included covariates for age, sex, years of education, annual household income, self-rated health, and mental health status assessed by the 5 -item Mental Health Index of the Japanese 36-item Short Form health survey. ${ }^{25}$

\section{Statistical Analysis}

To determine whether social isolation was associated with the JPCAT total score, we used a linear mixed effects model (random intercept model) that includes a random effect for clinic, and covariates (age, sex, years of education, annual household income, selfrated health, 5-item Mental Health Index score, and the proportion of isolated patients in each clinic) as fixed effects. The mixed effects model, based on a full information maximum likelihood estimation, was used to enable use of all the information including that from participants with some data missing. We calculated
95\% CIs using robust standard errors. In addition, we performed exploratory analyses to investigate the associations between social isolation and each domain score of the JPCAT using the same mixed effects models. For references, a 3-point increase in patient experience measures linearly scaled to a 0-100 range has been associated with a reduction in disenrollment from health plans, thus a difference of $>3$ points is considered sufficient in magnitude to have practical importance. $^{26-28}$ We used SPSS Statistics version 23 (IBM Corp) for statistical analyses.

\section{RESULTS}

Of the 644 adult participants who responded to the survey, we excluded 162 participants aged $<65$ years and 17 participants who did not have a usual source of care. We carried out analyses of the remaining 465 eligible participants.

Table 1 shows the characteristics of the 465 eligible participants. The majority of the participants were females $(54.4 \%)$, aged $\geq 70$ years $(71.8 \%)$, with less than college education $(79.3 \%)$, and with multimorbidity $(74.8 \%)$. The proportion of socially isolated patients was $27.3 \%$. The average JPCAT total score was 65.7 out of 100 points; the most highly scored

Table 1. Characteristics of Study Participants

\begin{tabular}{|c|c|c|c|c|}
\hline Characteristic & $\begin{array}{c}\text { Total } \\
(n=465)\end{array}$ & $\begin{array}{l}\text { Social Isolation Present } \\
\qquad(n=127)\end{array}$ & $\begin{array}{l}\text { Social Isolation } \\
\text { Absent }(n=298)\end{array}$ & $\begin{array}{l}\text { Data Missing } \\
\qquad(n=40)\end{array}$ \\
\hline \multicolumn{5}{|l|}{ Sex, N (\%) } \\
\hline Male & $200(43.0)$ & $67(52.8)$ & $126(42.3)$ & 7 (17.5) \\
\hline Female & $253(54.4)$ & $59(46.5)$ & 170 (57.0) & $24(60.0)$ \\
\hline Data missing & 12 & 1 & 2 & 9 \\
\hline \multicolumn{5}{|l|}{ Age, y, N (\%) } \\
\hline $65-69$ & $120(25.8)$ & $42(33.1)$ & $77(25.8)$ & $1(2.5)$ \\
\hline $70-79$ & $225(48.4)$ & $58(45.7)$ & $153(51.3)$ & $14(35.0)$ \\
\hline$\geq 80$ & $109(23.4)$ & $27(21.3)$ & $68(22.8)$ & $14(35.0)$ \\
\hline Data missing & 11 & 0 & 0 & 11 \\
\hline \multicolumn{5}{|l|}{ Education, N (\%) } \\
\hline$<$ High school & $135(29.0)$ & $37(29.1)$ & $85(28.5)$ & $13(32.5)$ \\
\hline High school & 192 (41.3) & $51(40.2)$ & $131(44.0)$ & $10(25.0)$ \\
\hline Junior college & $42(9.0)$ & $11(8.7)$ & $31(10.4)$ & $0(0.0)$ \\
\hline$\geq$ College & $64(13.8)$ & $20(15.7)$ & $41(13.8)$ & $3(7.5)$ \\
\hline Data missing & 32 & 8 & 10 & 14 \\
\hline \multicolumn{5}{|c|}{ Annual household income (million yen), N (\%) } \\
\hline$<2.00$ ( 18,000 US dollars) & $148(31.8)$ & $47(37.0)$ & $90(30.2)$ & $11(27.5)$ \\
\hline $2.00-4.99$ & $219(47.1)$ & $55(43.3)$ & $158(53.0)$ & $6(15.0)$ \\
\hline$\geq 5.00$ & $42(9.0)$ & $10(7.9)$ & $31(10.4)$ & $1(2.5)$ \\
\hline \multirow[t]{2}{*}{ Data missing } & 56 & 15 & 19 & 22 \\
\hline & & & & continues \\
\hline
\end{tabular}


Table 1. Characteristics of Study Participants (continued)

\begin{tabular}{|c|c|c|c|c|}
\hline Characteristic & $\begin{array}{c}\text { Total } \\
(n=465)\end{array}$ & $\begin{array}{l}\text { Social Isolation Present } \\
\qquad(n=127)\end{array}$ & $\begin{array}{l}\text { Social Isolation } \\
\text { Absent }(n=298)\end{array}$ & $\begin{array}{l}\text { Data Missing } \\
\quad(n=40)\end{array}$ \\
\hline \multicolumn{5}{|l|}{ Number of comorbidities, ${ }^{a} \mathrm{~N}(\%)$} \\
\hline 0 & $9(1.9)$ & $2(1.6)$ & $7(2.3)$ & $8(20.0)$ \\
\hline 1 & $89(19.1)$ & $22(17.3)$ & $59(19.8)$ & $11(27.5)$ \\
\hline$\geq 2$ & $348(74.8)$ & $100(78.7)$ & $226(75.9)$ & $11(27.5)$ \\
\hline Data missing & 19 & 3 & 6 & 10 \\
\hline \multicolumn{5}{|l|}{ Self-rated health, N (\%) } \\
\hline Excellent & $12(2.6)$ & $6(4.7)$ & $4(1.3)$ & $2(5.0)$ \\
\hline Very good & $75(16.1)$ & $29(22.8)$ & $39(13.1)$ & $7(17.5)$ \\
\hline Good & $277(59.6)$ & $64(50.4)$ & $193(64.8)$ & $20(50.0)$ \\
\hline Poor & $85(18.3)$ & $24(18.9)$ & $53(17.8)$ & $8(20.0)$ \\
\hline Very poor & $6(1.3)$ & $1(0.8)$ & $5(1.7)$ & $0(0.0)$ \\
\hline Data missing & 10 & 3 & 4 & 3 \\
\hline SF-36 Mental Health Index score, mean (SD) & $50.9(9.3)$ & $48.3(9.4)$ & $52.1(9.1)$ & $47.5(8.4)$ \\
\hline \multicolumn{5}{|l|}{ JPCAT, mean (SD) } \\
\hline Total score & $65.7(14.4)$ & $64.2(15.3)$ & $66.0(14.0)$ & $68.5(14.1)$ \\
\hline First contact & $50.6(24.8)$ & $50.9(22.8)$ & $48.9(25.3)$ & $63.3(24.0)$ \\
\hline Longitudinality & $81.2(15.4)$ & $78.8(17.5)$ & $81.9(14.5)$ & $83.7(14.6)$ \\
\hline Coordination & $70.2(24.6)$ & $70.9(23.6)$ & $70.4(25.0)$ & $66.4(24.7)$ \\
\hline Comprehensiveness (services available) & $70.0(21.5)$ & $66.9(23.0)$ & $71.2(20.8)$ & $71.9(20.9)$ \\
\hline Comprehensiveness (services provided) & $45.8(28.4)$ & $43.5(27.9)$ & $46.7(28.4)$ & $46.4(31.7)$ \\
\hline Community orientation & $74.0(17.7)$ & $71.0(18.7)$ & $75.5(16.9)$ & $73.0(19.8)$ \\
\hline
\end{tabular}

JPCAT = Japanese version of Primary Care Assessment Tool; SF-36 = Japanese 36-item short form health survey.

asimple counts of the following chronic conditions: hypertension, diabetes, dyslipidemia, stroke, cardiac diseases, chronic respiratory diseases, digestive diseases, kidney diseases, urologic diseases, arthritis, rheumatism, mental disorders, endocrine diseases, and malignancy.

domain was longitudinality with 81.2 points, and the most poorly scored domain was comprehensiveness (services provided) with 45.8 points. Table 1 also compares the characteristics of the socially isolated participants with participants who were not socially isolated. We noted a trend suggesting that the socially isolated participants had lower JPCAT scores and 5 -item Mental Health Index scores.

Table 2 shows the results of the linear mixed effects model, examining the associations between social isolation and the JPCAT scores as measures of patient experience in primary care. Social isolation was negatively associated with the JPCAT total score, after adjustment for possible confounders and clustering within clinics (mean difference $=-3.67 ; 95 \% \mathrm{CI}$, -7.00 to -0.38$)$. Among the JPCAT domain scores, social isolation was significantly ( $\mathrm{N}=465)$ associated with longitudinality, comprehensiveness (service provided), and community orientation scores. Comprehensiveness (service provided) had the strongest association with social isolation (mean difference $=-7.58 ; 95 \% \mathrm{CI},-14.28$ to -0.88 ).
Table 2. Associations Between Social Isolation and JPCAT Scores ${ }^{a}$

\begin{tabular}{|c|c|c|c|c|}
\hline Outcome & $\begin{array}{c}\text { Unadjusted } \\
\text { Mean Difference } \\
(95 \% \mathrm{Cl})\end{array}$ & $\begin{array}{c}P \\
\text { Value }\end{array}$ & $\begin{array}{c}\text { Adjusted }^{c} \\
\text { Mean Difference } \\
\text { (95\% Cl) }\end{array}$ & $\begin{array}{c}P \\
\text { Value }\end{array}$ \\
\hline JPCAT total score & $-3.43(-6.74$ to -0.12$)$ & .042 & $-3.67(-7.00$ to -0.38$)$ & .029 \\
\hline \multicolumn{5}{|l|}{ JPCAT domain scores } \\
\hline First contact & $1.83(-3.83$ to 7.48$)$ & .525 & $2.50(-3.24$ to 8.25$)$ & .392 \\
\hline Longitudinality & $-5.31(-8.77$ to -1.85$)$ & .003 & $-5.33(-8.79$ to -1.87$)$ & .003 \\
\hline Coordination & $-1.86(-7.77$ to 4.05$)$ & .536 & $-3.74(-9.63$ to 2.15$)$ & .212 \\
\hline $\begin{array}{l}\text { Comprehensiveness } \\
\text { (services available) }\end{array}$ & $-4.41(-9.71$ to 0.88$)$ & .102 & $-3.61(-8.97$ to 1.75$)$ & .186 \\
\hline $\begin{array}{l}\text { Comprehensiveness } \\
\text { (services provided) }\end{array}$ & $-6.36(-13.02$ to 0.31$)$ & .062 & $-7.58(-14.28$ to -0.88$)$ & .027 \\
\hline Community orientation & $-5.74(-9.86$ to -1.63$)$ & .006 & $-5.31(-9.51$ to -1.10$)$ & .014 \\
\hline \multicolumn{5}{|c|}{$\begin{array}{l}\text { JPCAT = Japanese version of Primary Care Assessment Tool; SF-36 = Japanese } 36 \text {-item short form health survey. } \\
\text { a Random intercept model; Reference group: not socially isolated. } \\
\text { b All scores range from } 0 \text { to } 100 \text {. } \\
\text { 'Adjusted for age, sex, years of education, annual household income, self-rated health, and SF-36 Mental Health } \\
\text { subscale score. }\end{array}$} \\
\hline
\end{tabular}




\section{DISCUSSION}

Our results revealed that social isolation was associated with a more negative patient experience of primary care, especially regarding longitudinality, comprehensiveness (services provided), and community orientation, among older Japanese patients who had a usual source of care. Based on previous results, a JPCAT total score difference of $>3$ points between socially isolated and not socially isolated patients in our study is considered sufficient in magnitude to have practical importance.

Our findings agree with previous exploratory study results about the associations between elements of social capital and patient experience. ${ }^{16,17}$ Although having a social network is a crucial element of social capital, the association between social isolation and patient experience has been unclear. The results of our study contribute additional information about potential mechanisms by which social isolation influences health outcomes and patient behaviors. According to a previous qualitative study, service providers experience substantial levels of concern and frustration and have a sense of powerlessness about meeting the needs of socially isolated patients ${ }^{29}{ }_{i}$ however, there remains a lack of relevant data on what their care needs are. Our study identified longitudinality, comprehensiveness, and community orientation as unmet needs in socially isolated elderly patients in primary care. These findings might be helpful for primary care providers to address the needs of socially isolated patients, further studies are needed.

To the best of our knowledge, this is the first study to reveal the association between social isolation and the patient's experience of primary care. Our findings were based on data from a nationwide multicenter primary care practice-based research network study covering both urban and rural areas and included a wide range of local health care delivery systems. Patient experiences differ by clinic; therefore, we adjusted clustering within clinics by using a mixed-effects model and allowed appropriate patient-level analysis.

Our study has several potential limitations. First, the participation rate was a concern. A previous study of patient experience surveys showed that a low participation rate did not introduce selective nonresponse bias, ${ }^{30}$ however, it is possible that patients with lower quality patient experiences or social networks were less likely to respond to our survey. If so, this could cause an underestimation of the association between social isolation and patient experience in this study. Second, in the validation study of the JPCAT, although socioeconomic factors were employed to ensure that the selection of the sampling site represented the Japanese national standard, the sampling site was restricted to 1 urban area. Therefore, there were differences in the participants' characteristics between the validation study of the JPCAT and this study that included rural practices. Construct validity of the JPCAT, however, has previously been verified in the population of this study. ${ }^{31,32}$ Third, our survey setting was restricted to primary care clinics that had a known interest in health care quality. Although we covered a nationwide network of primary care clinics, caution should be exercised when generalizing the results of this study.

In conclusion, social isolation was associated with negative patient experiences in elderly primary care patients. Raising awareness about the importance of patient social networks among primary care providers and targeted interventions for socially isolated elderly patients aimed at improving the experience of primary care, especially regarding longitudinality, comprehensiveness, and community orientation, may be warranted.

To read or post commentaries in response to this article, see it online at http://www.AnnFamMed.org/content/16/5/393.

Key words: social isolation; social capital; primary care/general practice; patient experience

Submitted November 5, 2017; submitted, revised, February 27, 2018; accepted March 22, 2018.

Funding support: Pfizer Health Research Foundation, Japan (grant no. 15-9-051).

Previous presentations: Preliminary results from this work have been presented at the North American Primary Care Research Group Annual Meeting; November 12-16, 2016; Colorado Springs, Colorado.

Acknowledgments: The authors thank the participating primary care clinics belonging to Japanese Health and Welfare Co-operative Federation and Japan Federation of Democratic Medical Institution.

Supplemental Materials: Available at http://www.AnnFamMed. org/content/16/5/393/suppl/DC1/.

\section{References}

1. Nicholson NR Jr. Social isolation in older adults: an evolutionary concept analysis. J Adv Nurs. 2009;65(6):1342-1352.

2. Kawachi I, Subramanian SV, Kim D. Social Capital and Health. New York, NY: Springer; 2008.

3. Berkman LF. Assessing the physical health effects of social networks and social support. Annu Rev Public Health. 1984;5:413-432.

4. Eng PM, Rimm EB, Fitzmaurice G, Kawachi I. Social ties and change in social ties in relation to subsequent total and cause-specific mortality and coronary heart disease incidence in men. Am J Epidemiol. 2002;155(8):700-709.

5. Boden-Albala B, Litwak E, Elkind MSV, Rundek T, Sacco RL. Social isolation and outcomes post stroke. Neurology. 2005;64(11): 1888-1892.

6. Mistry R, Rosansky J, McGuire J, McDermott C, Jarvik L; UPBEAT Collaborative Group. Social isolation predicts re-hospitalization in a group of older American veterans enrolled in the UPBEAT Program, Unified Psychogeriatric Biopsychosocial Evaluation and Treatment. Int J Geriatr Psychiatry. 2001;16(10):950-959. 
7. Faulkner KA, Cauley JA, Zmuda JM, Griffin JM, Nevitt MC. Is social integration associated with the risk of falling in older communitydwelling women? J Gerontol A Biol Sci Med Sci. 2003;58(10): M954-M959.

8. Béland F, Zunzunegui M-V, Alvarado B, Otero A, Del Ser T. Trajectories of cognitive decline and social relations. J Gerontol B Psychol Sci Soc Sci. 2005;60(6):320-330.

9. Hanson BS. Social network, social support and heavy drinking in elderly men-a population study of men born in 1914, Malmö, Sweden. Addiction. 1994;89(6):725-732.

10. Locher JL, Ritchie CS, Roth DL, Baker PS, Bodner EV, Allman RM. Social isolation, support, and capital and nutritional risk in an older sample: ethnic and gender differences. Soc Sci Med. 2005;60(4): 747-761.

11. Institute of Medicine. Committee on Quality of Health Care in America. Crossing the Quality Chasm: A New Health System for the 21st Century. Washington, DC: National Academies Press; 2001.

12. Lee Y-Y, Lin JL. The effects of trust in physician on self-efficacy, adherence and diabetes outcomes. Soc Sci Med. 2009;68(6): 1060-1068.

13. Little $P$, Everitt $H$, Williamson I, et al. Observational study of effect of patient centredness and positive approach on outcomes of general practice consultations. BMJ. 2001;323(7318):908-911.

14. Campbell JL, Ramsay J, Green J. Age, gender, socioeconomic, and ethnic differences in patients' assessments of primary health care. Qual Health Care. 2001;10(2):90-95.

15. Xiao H, Barber JP. The effect of perceived health status on patient satisfaction. Value Health. 2008;11(4):719-725.

16. Lindström M, Axén E. Social capital, the miniaturization of community and assessment of patient satisfaction in primary healthcare: a population-based study. Scand J Public Health. 2004;32(4):243-249.

17. Perry M, Williams RL, Wallerstein N, Waitzkin H. Social capital and health care experiences among low-income individuals. Am J Public Health. 2008;98(2):330-336.

18. Drennan V, Walters K, Lenihan P, Cohen S, Myerson S, Iliffe S; SPICE Research Group. Priorities in identifying unmet need in older people attending general practice: a nominal group technique study. Fam Pract. 2007;24(5):454-460.

19. Agency for Healthcare Research and Quality. Primary care practicebased research networks. https://www.ahrq.gov/research/findings/ factsheets/primary/pbrn/index.html. Accessed Oct 2, 2017.
20. Aoki T, Inoue M, Nakayama T. Development and validation of the Japanese version of Primary Care Assessment Tool. Fam Pract. 2016; 33(1):112-117.

21. Shi L, Starfield B, Xu J. Validating the adult primary care assessment tool. J Fam Pract. 2001;50(2):161-175.

22. Kurimoto A, Awata S, Ohkubo T, et al. [Reliability and validity of the Japanese version of the abbreviated Lubben Social Network Scale]. Nihon Ronen Igakkai Zasshi. 2011;48(2):149-157.

23. Lubben J, Blozik E, Gillmann G, et al. Performance of an abbreviated version of the Lubben Social Network Scale among three European community-dwelling older adult populations. Gerontologist. 2006;46(4):503-513.

24. Starfield B. Primary Care: Balancing Health Needs, Services, and Technology. Oxford, UK: Oxford University Press; 1998.

25. Fukuhara S, Bito S, Green J, Hsiao A, Kurokawa K. Translation, adaptation, and validation of the SF-36 Health Survey for use in Japan. J Clin Epidemiol. 1998;51(11):1037-1044.

26. Lied TR, Sheingold SH, Landon BE, Shaul JA, Cleary PD. Beneficiary reported experience and voluntary disenrollment in Medicare managed care. Health Care Financ Rev. 2003;25(1):55-66.

27. Paddison CAM, Elliott MN, Haviland AM, et al. Experiences of care among Medicare beneficiaries with ESRD: Medicare Consumer Assessment of Healthcare Providers and Systems (CAHPS) survey results. Am J Kidney Dis. 2013;61(3):440-449.

28. Warren FC, Abel G, Lyratzopoulos G, et al. Characteristics of service users and provider organisations associated with experience of out of hours general practitioner care in England: population based cross sectional postal questionnaire survey. BMJ. 2015;350:h2040.

29. Russell C, Schofield T. Social isolation in old age: a qualitative exploration of service providers' perceptions. Ageing Soc. 1999; 19(1):69-91.

30. Roland M, Elliott M, Lyratzopoulos G, et al. Reliability of patient responses in pay for performance schemes: analysis of national General Practitioner Patient Survey data in England. BMJ. 2009;339: b3851.

31. Aoki T, Miyashita J, Yamamoto Y, et al. Patient experience of primary care and advance care planning: a multicentre cross-sectional study in Japan. Fam Pract. 2017;34(2):206-212.

32. Aoki T, Yamamoto $Y$, Ikenoue $T$, et al. Effect of patient experience on bypassing a primary care gatekeeper: a multicenter prospective cohort study in Japan. J Gen Intern Med. 2018;33(5):722-728. 